\author{
Assistant Professor Florentina BALU, PhD \\ University of Geneva, Switzerland \\ Julien FROIDEVAUX, CFA \& PhD \\ University of Geneva, Switzerland \\ Professor Florina BRAN, PhD \\ The Bucharest University of Economic Studies \\ Associate Professor Carmen Valentina RĂDULESCU, PhD \\ The Bucharest University of Economic Studies \\ Associate Professor Dumitru Alexandru BODISLAV, PhD \\ The Bucharest University of Economic Studies
}

\title{
INDEPENDENT ASSETS MANAGERS IN SWISS FINANCIAL MARKET. MODELLING, COMPUTATION AND OPTIMIZATION OF IAM PERFORMANCE AND CUSTOMER SATISFACTION
}

Abstract: The market size of financial intermediaries in Switzerland is estimated at around CHF 500-600 billion (independent assets managers (IAM) only), comparable amount with Swiss pension funds' assets. This is the equivalent of one account out of eight opened in local banks. However, the new regulation and increasing regulatory costs force IAM to merge and make use of synergies in the area of compliance and risk management. The main purpose of this paper is to better understand the role of IAM within the Swiss financial market, and to identify the key drivers of its attraction model. Based on traditional qualitative and quantitative research methods (structural equation modelling, partial least square approach), the paper designs, develops and analyses different PLS models to identify the key drivers of IAM performance and customers' satisfaction. It presents into details the results of the identified optimal model used to maintain the IAM attractiveness within the competitive financial landscape after the elimination of Swiss banking secrecy protection.

Key words: independent asset managers, SEM-PLS modelling, Swiss financial market, performance and customers' satisfaction, IAMs attractiveness' key drivers.

JEL Classification: C51, M10, G21, G17

\section{Present context and importance of the subject}

The market size of financial intermediaries in Switzerland is estimated at around CHF 500-600 billion (independent managers only). The number of independent managers in Switzerland is estimated to be between 2000 and 6000 depending on whether regulated players or other trusted advisors are considered. In terms of 
Florentina Balu, Julien Froidevaux, Florina Bran, Carmen Valentina Rădulescu, Dumitru Alexandru Bodislav

number of managed accounts, within the banks proposing an activity to independent managers, according to several cross-checks carried out by authors, an average of one account out of seven to one account out of ten is managed externally, or respectively between $10 \%$ and $15 \%$ of the assets deposited by independent asset managers.

The expertise and reliability of the Swiss asset managers continue to be valued and highly appreciated around the world. Most Independent Asset Managers in Switzerland were created by individual private bankers or small teams of bankers who left banks to start up their own firms, using banks as custodians to house client assets. With extensive experience and long-established client relationships in most cases, the independent asset management (IAM) advisors deeply understand the business when joining or forming an IAM, and their experience is valuable to clients. The core of their business approach is to focus on client needs as well asto deliver potential solutions conforming to clients' highest expectations. This is in fact, the heart of their value proposition: independence, aligned interest, and personal service."They offer clients a range of wealth management solutions and advice, with asset management at the core. IAMs vary in their asset management approaches, from active managers who select individual stocks and bonds for clients to more passive strategies that utilize funds in line with the asset allocation for clients. IAMs also offer recommendations on alternative investments, including hedge funds, private equity, commodities, and real estate". (Robins, Gregg, 2015).

Table 1. Swiss IAM Tiers at a glance

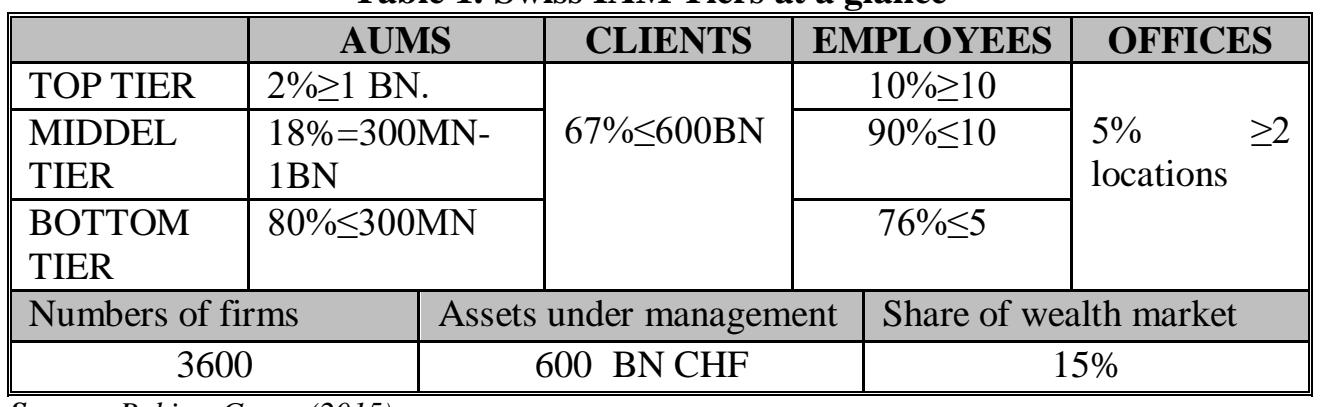

Source: Robins, Gregg (2015)

The number of bank employees in Switzerland is still estimated at around 100,000 today. These generate approximately $15 \%$ of the country's tax revenues. This proportion is close to $20 \%$ in banking centers such as Zurich and Geneva. In Geneva alone, there are about 37,000 jobs in the financial sector, including 19,000 in banks, 5,600 in other financial intermediaries, and 2,800 in the sole manager (REG, 2015). At the Swiss level, 266 banks represented a workforce of 123,889 people in 2015 (National Bank of Switzerland, 2015). In total, the financial sector in Switzerland accounts for 10\% of GDP, this has been constant since 1995. What about the global wealth management market? 
Independent Assets Managers in Swiss Financial Market. Modelling, Computation and Optimization of IAM Performance and Customer Satisfaction

According to consultant Boston Consulting Group (BCG), in its annual report on private wealth management (BCG, 2015) at the end of 2015, total private wealth amounts totaled USD 168 trillion, still growing (USD 148 trillion in 2013). In terms of geographical distribution, the United States still remains the main market (geographical distribution around of USD 168 trillion): USA USD 60 trillion; Latin America USD 5 trillion; Western Europe USD 41 trillion; Eastern Europe USD 4 trillion; Japan USD 13 trillion; Asia Pacific USD 37 trillion (the only region with double-digit growth);Africa and Middle East USD 8 trillion. For offshore management (e.g. funds deposited and managed in a country other than that of the customer's residence) only, it represents (still according to BCG) 10 trillion USD out of a total of 168 trillion USD. The main offshore management centers include the following countries Switzerland (about 25\% of offshore assets), England, Panama and the Caribbean. There is significant growth in offshore management in Asia, particularly in the Hong Kong and Singapore markets. In the post-war period until the early 2000s, for a large portion of the offshore managed clients, the financial performance of Swiss-based financial intermediaries was excellent compared to most other markets.

Several factors can explain this outperformance:

- A tradition of management in Switzerland for several centuries, with the local presence since the 17th century of a large population of European exiles;

- Absence of participation in the major European conflicts of the 19th and 20th centuries and destruction thereof;

- An absence of internal conflicts since the middle of the 19th century;

- The presence of a bank secrecy included in the main banking law of 1934;

- The stability of the Swiss Franc against other European currencies in the absence of frequent devaluations;

- The absence of hyperinflation usually present in the markets of the former emerging countries.

The succession of changes observed in the markets since the 2000s has had several serious consequences for a financial centre which, for more than a century, clearly dominated all the other international banking centres in offshore private management:

- A significant reduction in management margins;

- A need for greater transparency;

- An increase in training and accountability requirements;

- Increasingly complex and costly regulatory requirements.

Despite these changes, the financial centre has shown significant resilience and has maintained its status as the leading offshore private wealth management company in the world. To maintain this situation, Switzerland has had to introduce several major reforms to maintain its competitiveness. In particular, it has to put in place a series of provisions to give a strict framework to cross-border activities. The need 
Florentina Balu, Julien Froidevaux, Florina Bran, Carmen Valentina Rădulescu, Dumitru Alexandru Bodislav

to respect foreign law and no longer be in an illegal situation in the context of prospecting but also maintaining banking relationships has been validated and framed as never before (FINMA, 2010).

All these changes obviously apply to independent managers who can no longer claim different treatment from other financial intermediaries. In the same vein, banks can no longer use "close" independent managers to circumvent these requirements.

In general, the attractiveness is also decreasing for the framework conditions of the Geneva financial centre (or at least the local perception of this attractiveness). As illustrated by the latest economic survey prepared by the Geneva Financial Centre Foundation, several results show a net decrease of attractiveness perceived either by the banks or by the independent managers. For example, for non-Swiss customers, a decrease of attractiveness between $40 \%$ and $60 \%$ is noted in 2015 according to the independent managers questioned (worse still, more than $80 \%$ in particular for European customers of banks over 200 employees - Fondation Genève Place Financière, 2016). More complex, the overall attractiveness of the place for private customers is judged to be sharply lower in 2015 (64\% decline according to the independent managers, between $33 \%$ and $92 \%$ depending on the banks - Fondation Genève Place Financière, 2016).

Even if the perception of attractiveness is decreasing, it is clearly in the interest of the Swiss financial centre to actively defend its always privileged place in global offshore management.

In this context, the main objective of this paper is to identify the key drivers of performance and customers' satisfaction within an Independent Assets Management Company. We start from the general agreed hypothesis that the independence of a financial intermediary such as an independent asset manager (compared with a traditional banking institution) leads to better results in terms of portfolio management and better quality services for customers. After our knowledge, there is currently no other research covering as broadly independent asset managers in Switzerland, in terms of business modelling, computation and optimization of performance and customer satisfaction. The case study presented in our paper aims to reduce this academic gap as well as bring added value knowledge for academics and professionals.

From the beginning, we would like to emphasis that, in this paper, the meaning of performance should be interpreted broadly with a multi-criteria approach (i.e. added value services in the context of an IAM company). The paper proposes a unique approach, through rigorous research, creation of SEM-PLS regression models, and specific contribution of the authors, who have in-depth knowledge of the independent asset managers market, especially in the three main axes discussed in the current research (company structure, asset management, and customer relations). 
Independent Assets Managers in Swiss Financial Market. Modelling, Computation and Optimization of IAM Performance and Customer Satisfaction

\section{Literature review}

In their seminal work, Jensen and Meckling (1976) argue that managers' behaviour is directly linked to the contractual agreement they have with the company, including specific ownership they may have, and that agency costs are as important as direct costs. Jensen (1983) further develops the importance of accounting practices for company structure. Eisenhardt (1989) offers a full review of agency theory and implications, especially in the field of management, information technology, and risk management. Williamson (2002) points out that the companies should be analysed through contract and governance, not only legal structure. Conflict of interest is closely related to agency theory, as there is a natural state of conflict of interest in financial intermediation between agents and principals, as covered for instance in Palazzo and Rethel (2012). Schulze, Lubatkin, Dino and Buchholtz (2001) further point out that agency costs are reduced in family owned structures, given the proximity and alignment of interests between owners and managers.

Furthermore, the impact of Board of Directors on the efficiency of a company structure is very well covered, as in Adams, Mansi and Nishikawa (2010), Driscoll (2001), Radin and Stevenson (2006), Rutherford and Buchholtz, Brown (2007), Ferris and Yan (2007), or Walsh and Seward (1999). All authors point out various correlations between the size of a Board, the experience of members, the number of externs, quality of information provided, and independence, to mention a few.

Moreover, Begg (2009) has shown the limits of regulations passed in Europe after the financial crisis of 2008. In order to match MIFID requirements, Switzerland will witness in 2017 the approval of two new essential regulations (Federal Financial Services Act and Financial Institutions Act), which will have a lasting impact on the financial environment, including for financial intermediaries. As pointed out by Thévenoz (2016), the tax environment in Switzerland has also undergone changes unseen beforehand, including a new law regarding automatic exchange of information (or Common Reporting Standards as coined under OECD supervision).

Financial intermediaries have been largely benefiting from indirect remuneration (retrocessions) for many years, until further transparency has been imposed by various legal decisions by Swiss courts, as summed up in various articles between 2007 and 2016 (see for instance Bahar and Thévenoz (2006 and 2007), BrettonChevallier (2008), Fischer (2011), and Thévenoz (2016)). Academic studies argue that retrocessions can be beneficial to the industry (for instance Stoughton and Wu Zechner (2011)) or not as in Inderst and Ottaviani (2012). Chevalier and Ellison (1999) and Golec (1996) argue that there is a positive correlation between the performance of a fund and the characteristics of the fund manager, whereby younger managers perform better. 
Florentina Balu, Julien Froidevaux, Florina Bran, Carmen Valentina Rădulescu, Dumitru Alexandru Bodislav

In addition, many studies cover the relationship between incentives of the portfolio managers and performance, such as Petersen (1993) or Ward, Brown, and Rodriguez (2009). Specifically, the ownership of shares by the fund managers is thought to lead to superior performance, as expressed by Evans (2008) and Cremers et al. (2009). However, the risk of a portfolio can be impacted during the financial year with inappropriate incentives or risk management as pointed out by Kempf, Ruenzi, and Thiele (2009). Finally, an active governance is on the other hand positively correlated with performance, as pointed by Chou, $\mathrm{Ng}$ and Wang (2010). Private clients need include capital preservation, security, fiscal efficiency, discretion, as pointed out for instance by Walter (2015). Furthermore, private clients do act differently that institutional, as pointed out by Keswani and Stolin (2012).

\section{Methodology research}

In order to identify the key drivers of performance and client satisfaction, that represent in fact, the core solution to maintain the high attractiveness of Swiss market of IAM, our study use SEM approach.

Structural equation modelling (SEM) is a statistical multivariate technique for testing and estimating causal relationships using a combination of statistical data and qualitative causal assumptions. This technique combines aspects of statistical multivariate techniques such as: multiple regression and factor analysis, but is distinguished by two characteristics: (1) estimation of multiple and interrelated dependence relationships, and (2) the ability to represent unobserved concepts in these relationships and account for measurement error in the estimation process.

SEM is based on causal relationships, in which the change in one variable is assumed to result in a change in another variable. For a mathematical simple representation of the causal relationships between variables, the matrices are used to build the fundamental equations both for structural model and measurement model.

\subsection{The equation for structural model}

Structural model describes certain relationships among the exogenous and endogenous latent variables. This model can give us the responses at the following three questions: (1) Are endogenous variables related to the predictor (exogenous) variables?; (2) Exactly how strong is the influence of each exogenous variable on endogenous variable?; (3) How well does the model fit the data?.

Mathematically, the structural model is represented in the following equation:

$$
\eta=\beta \eta+\Gamma \xi+\zeta,
$$

where:

- $\eta$ stands for the vector of dependent latent variables (dimension $m \times 1$ ),

- $\xi$ is the vector of the independent latent variables (dimension $n \times 1$ ), 
Independent Assets Managers in Swiss Financial Market. Modelling, Computation and Optimization of IAM Performance and Customer Satisfaction

- $\zeta$ is the inner vector of residual variance or the vector of residual variables (dimension $m \times 1$, that is assumed to have an expected value of zero and which is uncorrelated with $\xi$ ),

- $\mathrm{m}, \mathrm{n}$ are the number of exogenous, and respectively, of endogenous constructs,

- $\beta$ is the $m \times m$ coefficient matrix showing the influence of the latent dependent variables on each other,

- $\Gamma$ is the $m \times n$ coefficient matrix for the effects of $\xi$ on $\eta$.

More detailed the structural model can be represented as in the following relation:

$\left(\begin{array}{l}\eta_{1} \\ \eta_{2} \\ \mathrm{M} \\ \eta_{i} \\ \mathrm{M} \\ \eta_{m}\end{array}\right)=\left(\begin{array}{cccccc}\beta_{11} & \beta_{12} & \Lambda & \beta_{1 j} & \Lambda & \beta_{1 m} \\ \beta_{21} & \beta_{22} & \Lambda & \beta 2 j & \Lambda & \beta_{2 m} \\ \mathrm{M} & & & & & \\ \beta_{i 1} & \beta_{i 2} & \Lambda & \beta i j & \Lambda & \beta_{i m} \\ \mathrm{M} & & & & & \\ \beta_{m 1} & \beta_{m 2} & \Lambda & \beta_{m j} & \Lambda & \beta_{m m}\end{array}\right) \times\left(\begin{array}{c}\eta_{1} \\ \eta_{2} \\ \mathrm{M} \\ \eta_{i} \\ \mathrm{M} \\ \eta_{m}\end{array}\right)+\left(\begin{array}{llllll}\gamma_{11} & \gamma_{12} & \Lambda & \gamma_{1 h} & \Lambda & \gamma_{1 n} \\ \gamma_{21} & \gamma_{22} & \Lambda & \gamma_{2 h} & \Lambda & \gamma_{2 n} \\ \mathrm{M} & & & & & \\ \gamma_{i 1} & \gamma_{i 2} & \Lambda & \gamma_{i h} & \Lambda & \gamma_{i n} \\ \mathrm{M} & & & & & \\ \gamma_{m 1} & \gamma_{m 2} & \Lambda & \gamma_{m h} & \Lambda & \gamma_{m n}\end{array}\right) \times\left(\begin{array}{c}\xi_{1} \\ \xi_{2} \\ \mathrm{M} \\ \xi_{h} \\ \mathrm{M} \\ \xi_{n}\end{array}\right)+\left(\begin{array}{c}\zeta_{1} \\ \zeta_{2} \\ \mathrm{M} \\ \zeta_{i} \\ \mathrm{M} \\ \zeta_{m}\end{array}\right)$.

\subsection{The equations for measurement model}

Measurement model specifies the relationship between the latent variables and the observed variables. This model can give us the responses at the following three questions: (1) To what extent are the observed variables actually measuring the hypothesized latent variables?; (2) Which observed variable is the best measure of a particular latent variable?; (3) To what extent are the observed variables actually measuring something other than the hypothesized latent variable?

Mathematically, we can write this model as in the below equations:

Where:

$$
\begin{aligned}
& x=\Lambda_{x} \xi+\delta \\
& y=\Lambda_{y} \eta+\varepsilon
\end{aligned}
$$

- $x$ is the vector of exogenous manifest variables $(p \times 1)$,

- $y$ is the vector of endogenous manifest variables $(q \times 1)$,

- $\xi$ is a vector of the independent latent variables $(n \times 1)$,

- $\eta$ is the vector of dependent latent variables $(m \times 1)$,

- $p$ is the number of exogenous construct indicators,

- $\mathrm{q}$ is the number of endogenous constructs indicators,

- $\Lambda_{\mathrm{x}}$ (dimension $p \times n$ ) and $\Lambda_{\mathrm{y}}$ (dimension $q \times m$ ) are the loadings matrices indicating simple regression coefficients linking the latent variables and their indicators; (Lambda X - correspondence (loadings) of exogenous indicators; Lambda Y-correspondence (loadings) of endogenous indicators) 
Florentina Balu, Julien Froidevaux, Florina Bran, Carmen Valentina Rădulescu, Dumitru Alexandru Bodislav

- Consecutively, the remaining variance for the manifest variables $\delta$ and $\varepsilon$ can be translated as measurement errors or noise.

More detailed the measurement model can be represented as follows:

$$
\begin{aligned}
& \left(\begin{array}{c}
X_{1} \\
X_{2} \\
\mathrm{M} \\
X_{i} \\
\mathrm{M} \\
X_{p}
\end{array}\right)=\left(\begin{array}{cccccc}
\lambda^{x}{ }_{11} & \lambda^{x}{ }_{12} & \Lambda & \lambda^{x}{ }_{1 j} & \Lambda & \lambda^{x}{ }_{1 n} \\
\lambda^{x}{ }_{21} & \lambda^{x}{ }_{22} & \Lambda & \lambda^{x}{ }_{2 j} & \Lambda & \lambda^{x}{ }_{2 n} \\
\mathrm{M} & & & & & \\
\lambda^{x}{ }_{i 1} & \lambda^{x}{ }_{i 2} & \Lambda & \lambda^{x}{ }_{i j} & \Lambda & \lambda^{x}{ }_{i n} \\
\mathrm{M} & & & & & \\
\lambda^{x}{ }_{p 1} & \lambda^{x}{ }_{p 2} & \Lambda & \lambda^{x}{ }_{p j} & \Lambda & \lambda^{x}{ }_{p n}
\end{array}\right) \times\left(\begin{array}{c}
\xi_{1} \\
\xi_{2} \\
\mathrm{M} \\
\xi_{i} \\
\mathrm{M} \\
\xi_{p}
\end{array}\right)+\left(\begin{array}{c}
\delta_{1} \\
\delta_{2} \\
\mathrm{M} \\
\delta_{i} \\
\mathrm{M} \\
\delta_{p}
\end{array}\right) \text {, and } \\
& \left(\begin{array}{c}
Y_{1} \\
Y_{2} \\
\mathrm{M} \\
Y_{i} \\
\mathrm{M} \\
Y_{q}
\end{array}\right)=\left(\begin{array}{cccccc}
\lambda^{y}{ }_{11} & \lambda^{y}{ }_{12} & \Lambda & \lambda^{y}{ }_{1 j} & \Lambda & \lambda^{y}{ }_{1 m} \\
\lambda^{y}{ }_{21} & \lambda^{y}{ }_{22} & \Lambda & \lambda^{y}{ }_{2 j} & \Lambda & \lambda^{y}{ }_{2 m} \\
\mathrm{M} & & & & & \\
\lambda^{y}{ }_{i 1} & \lambda^{y}{ }_{i 2} & \Lambda & \lambda^{y}{ }_{i j} & \Lambda & \lambda^{y}{ }_{i m} \\
\mathrm{M} & & & & & \\
\lambda^{y}{ }_{q 1} & \lambda^{y}{ }_{q 2} & \Lambda & \lambda^{y}{ }_{q j} & \Lambda & \lambda^{y}{ }_{q m}
\end{array}\right) \times\left(\begin{array}{c}
\eta_{1} \\
\eta_{2} \\
\mathrm{M} \\
\eta_{i} \\
\mathrm{M} \\
\eta_{q}
\end{array}\right)+\left(\begin{array}{c}
\varepsilon_{1} \\
\varepsilon_{2} \\
\mathrm{M} \\
\varepsilon_{i} \\
\mathrm{M} \\
\varepsilon_{q}
\end{array}\right) .
\end{aligned}
$$

\subsection{PLS Path Modelling algorithm}

In order to understand the Partial Least Square (PLS) technique for SEM, Chin (1998) studies a simple hypothetical two-block model, referring to the state where two blocks of indicators are summarizing some fundamental issue or construct. In PLS language this is similar to two latent variables each being represented by a block of indicators/variables. The following figure (Figure 2) illustrates a path diagram of a two-block model with two variables per block.

Figure 1. Two-structure model with reflective indicators

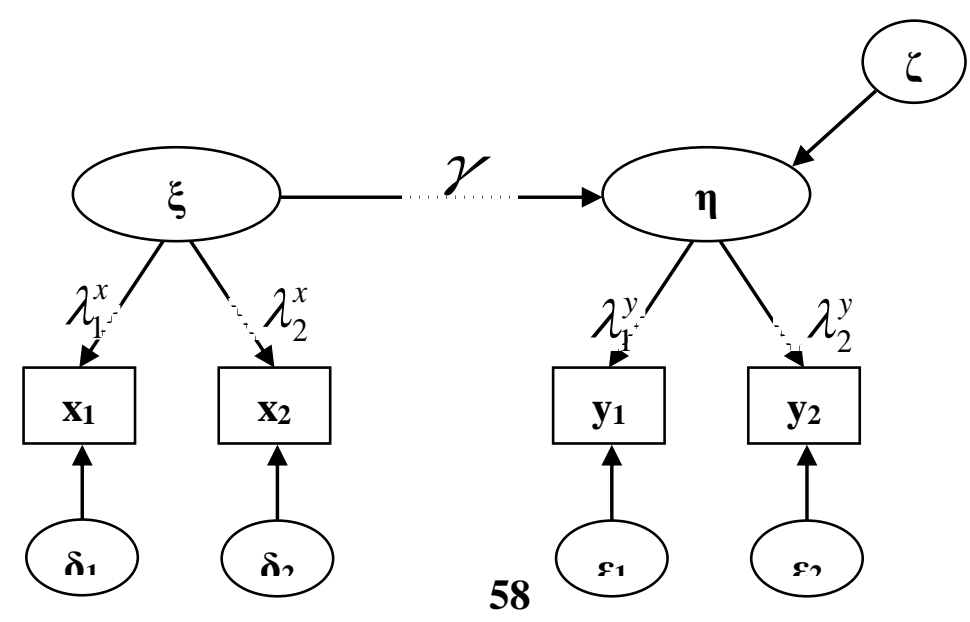

DOI: $10.24818 / 18423264 / 52.2 .18 .04$ 
Independent Assets Managers in Swiss Financial Market. Modelling, Computation and Optimization of IAM Performance and Customer Satisfaction

In above figure, the variables $\left(\mathrm{x}_{1}, \mathrm{x}_{2}, \mathrm{y}_{1}, \mathrm{y}_{2}\right)$, representing observed indicators, are illustrated as influenced by two distinct (i.e., orthogonal) factors labelled as the underlying constructs $\xi$ and $\eta$, including an error term $\zeta$. The degree to which these indicators are capable of describing their respective construct is revealed to a large extent by the power of the loadings $\left(\lambda_{1}^{x}, \lambda_{2}^{x}, \lambda_{1}^{y}\right.$, and $\left.\lambda_{2}^{y}\right)$.

When building up path diagrams, it is essential to take into account the path relations among blocks as well as between blocks and their respective indicators. In above example, the assumption is a one-way causal relationship between two constructs $(\xi$ and $\eta)$. Inasmuch as $\xi$ can only account for a fraction of the variance in $\eta$, the residual variance at this structural level is supposed to be inherent in $\zeta$. Given a sample series of observed variables, the objective is to work out a procedure for approximating parameters for the measurement model (factor loadings $\lambda_{1}^{x}, \lambda_{2}^{x}, \lambda_{1}^{y}$, and $\lambda_{2}^{y}$ ) and structural model (path coefficient between the endogenous and exogenous variables $\gamma$ and residual variance $\zeta$ ).

The PLS method commences with the aim of determining values of the latent variables for predictive intentions. From this viewpoint, the model from Figure 2 is regarded and used in a different way. Rather than using the model for explaining the covariation of all the variables, it is being altered to minimizing the variance of all latent variables. Therefore, parameter results are computed derived from the facility to minimize the residual variances of latent and observed variables.

Overall, all latent variable path models in PLS consist of three suites of relations: (1) the inner model, which describes the links between latent variables, (2) the outer model, which identifies the associations between latent variables and their associated manifest or observed variables, and (3) the weight relations whereupon case values for the latent variable can be estimated. To start with, it can be supposed that latent variables and manifest variables are normalized thus scaled to zero means and unit variances so that the constant parameter terms can be removed in the following equations.

\section{Case Study}

As indicated in the description of the PLS approach, the internal and external relations are based on structural equations. Consequently, the PLS approach makes it possible to analyse the equations that explain the relationships between the indicators with the corresponding axis (external model) and between the axes or the strategic perspectives (internal model). These equations can be applied to study the optimal relationships between each variable and identify the cause-effect-relation between many variables. 
Florentina Balu, Julien Froidevaux, Florina Bran, Carmen Valentina Rădulescu, Dumitru Alexandru Bodislav

From a practical point of view, this method allows for multiple applications, as in our case study, the identification of the most important factors than can better anticipate the following actions:

- Better allocation of internal resources in terms of organization of the company structure (current and future);

- Internal communication targeted to the real needs of the clients (for a focus on what is really important);

- The anticipation of new strategic factors and indicators (or potentially the strengthening of existing factors);

- The ability to view developments to be anticipated for a future strategy

The advantage of PLS approach applied in our case study is that it allows the development of the most appropriate model in terms of cause and effect, by iterations, analysing all the possibilities of combining axes and variables. The database was constructed using data collecting from twenty independent asset managers (IAM) from Switzerland as well as on a base of a questionnaire survey distributed to many bankers working within these companies. The survey was structured in three main parts: company structure, portfolio asset management and customer's satisfaction. Applying the PLS-SEM methodology to one of the above IAM Company, called hereby ABCD (database with a set of 146 variables), we developed and tested many alternative models in order to identify the key drivers of its performance and customers satisfactions. In this paper we present only four of them: two simplified model and two more detailed models. Among all developed models, only one was selected as the optimal model based on the assessment criteria of PLS-SEM approach.

Model I. The first model was developed using the survey structure checked by IAM specialists with extensive experience in Swiss wealth management industry. As we can see in its illustrative map (displayed below), in this model four main axes was identified: company structure, asset management, customer services, and independence. The notion of independence is added as an axis on the basis of variables distributed in several questions. 
Independent Assets Managers in Swiss Financial Market. Modelling, Computation and Optimization of IAM Performance and Customer Satisfaction

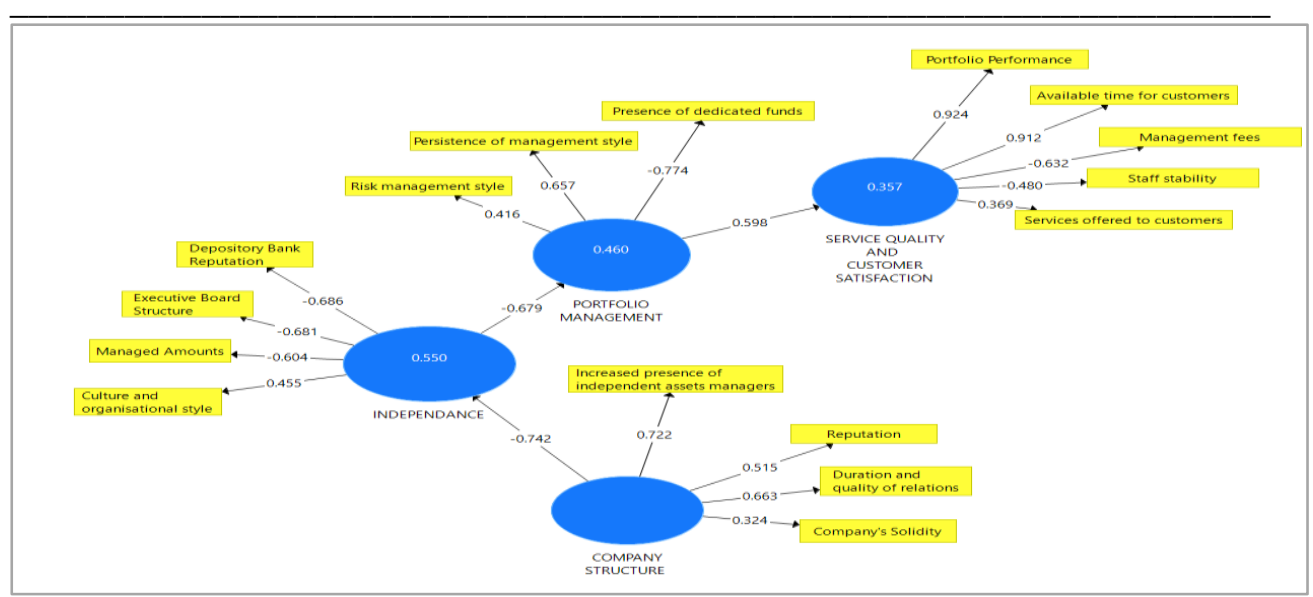

Source: own computations

Figure 2 - Model I

Model II. It is also based on the survey structure, but this time cause-effects relations between the main four axes and their associated indicators was established based on bootstrap simulation that gave us the possibility to identify and select the optimal model, from the generation of a series of models with four axes and different cause-effects ways.

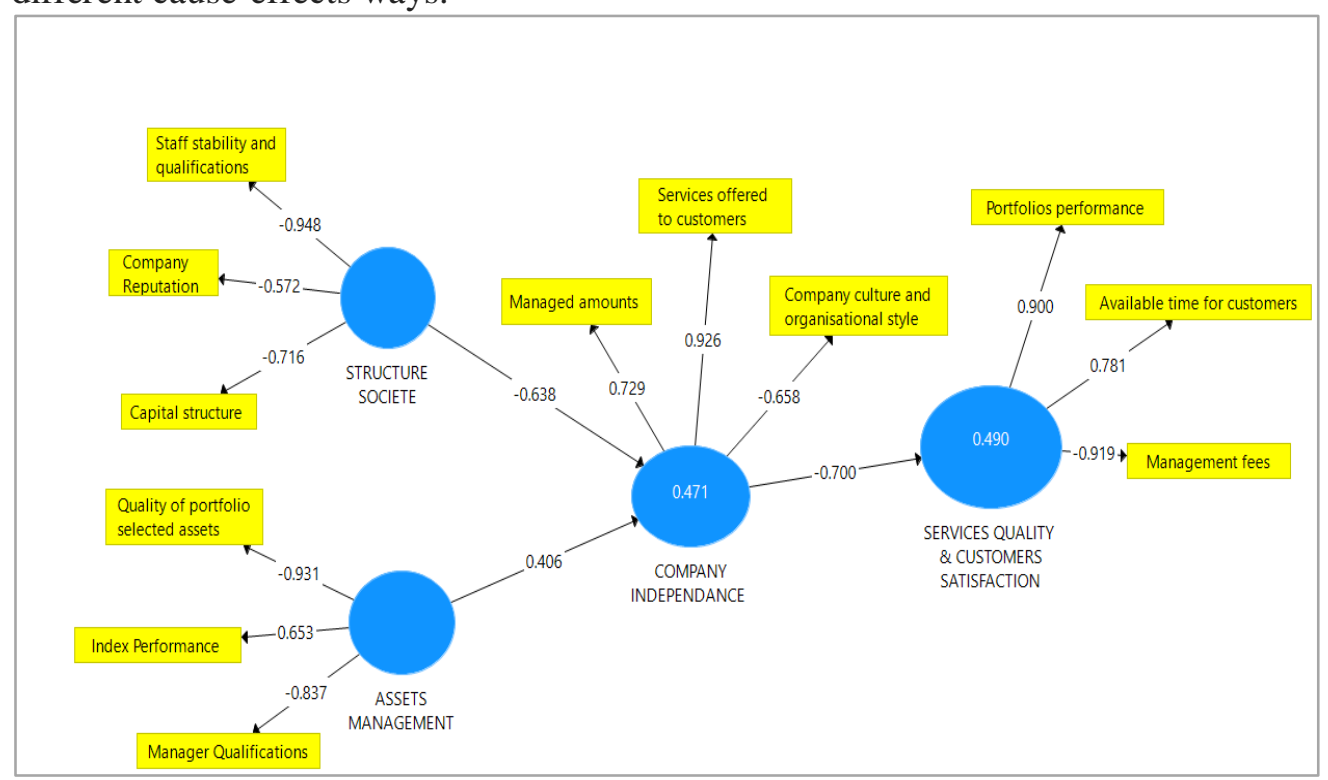

Figure 3 - Model II

Source: own computations 
Florentina Balu, Julien Froidevaux, Florina Bran, Carmen Valentina Rădulescu, Dumitru Alexandru Bodislav

Model III. It was developed based on a preliminary analysis of principal component analysis that indicates an improved model with seven axes that can be extracted. It allows us to reduce the number of variables from our initial database. The number of axes corresponding to latent variables depends on their explanatory power. Also, the selection of the variables for each axe was based on the same PCA technique. The matrix below shows the components that determine the variance of each variable with respect to the selected axes. The first 11 components listed in the diagram and table above, represents a cumulative variance of over $95 \%$. The first 7 components (the selected axes) represent a cumulative variance of more than $83 \%$, which can be expressed as a validation (or explanatory power) of more than $83 \%$ of the chosen model.

Table 3. Model III and Model IV - Variance and Cumulative Variance

\begin{tabular}{|l|r|r|r|r|r|r|}
\hline \multicolumn{7}{|c|}{ Total Variance Explained } \\
\hline & \multicolumn{3}{|c|}{ Initial Eigenvalues } & \multicolumn{2}{|c|}{ Extraction Sums of Squared Loadings } \\
\cline { 2 - 7 } Component & \multicolumn{1}{|c|}{ Total } & \% of Variance & Cumulative \% & Total & \% of Variance & Cumulative \% \\
\hline 1 & 8.958 & 21.850 & 21.850 & 8.958 & 21.850 & 21.850 \\
2 & 6.776 & 16.526 & 38.376 & 6.776 & 16.526 & 38.376 \\
3 & 5.228 & 12.752 & 51.128 & 5.228 & 12.752 & 51.128 \\
4 & 3.855 & 9.402 & 60.530 & 3.855 & 9.402 & 60.530 \\
5 & 3.502 & 8.542 & 69.072 & 3.502 & 8.542 & 69.072 \\
6 & 3.068 & 7.484 & 76.555 & 3.068 & 7.484 & 76.555 \\
7 & 2.817 & 6.870 & 83.426 & 2.817 & 6.870 & 83.426 \\
8 & 2.093 & 5.104 & 88.530 & 2.093 & 5.104 & 88.530 \\
9 & 1.338 & 3.265 & 91.794 & 1.338 & 3.265 & 91.794 \\
10 & 1.118 & 2.728 & 94.522 & 1.118 & 2.728 & 94.522 \\
11 & 1.009 & 2.460 & 96.982 & 1.009 & 2.460 & 96.982 \\
12 & .789 & 1.925 & 98.906 & & & \\
13 & .448 & 1.094 & 100.000 & & & \\
14 & $2.517 \mathrm{E}-15$ & $6.140 \mathrm{E}-15$ & 100.000 & & & \\
15 & $1.270 \mathrm{E}-15$ & $3.098 \mathrm{E}-15$ & 100.000 & & & \\
\hline
\end{tabular}

Source: own computations

Model IV - The Optimal Model. In fact, this model is an improved version of model III. It represents the optimal model version of the model with seven axes developed based on the PCA technique (it's an issue of a combinatorial nature). The seven selected axes were the following: Axis 1 - External factors; Axis 2 Independence of society; Axis 3 - Performance and customer satisfaction; Axis 4 Asset Management Model; Axis 5 - Customer characteristics; Axis 6 - Customer Service; Axis 7 - Structure of the management company.

From statistically point of view, this model represents the model with the highest power of explanation and the optimal one, as validated using the PLS-SEM assessment criteria. After our decision regarding the number of axes, we made a 
Independent Assets Managers in Swiss Financial Market. Modelling, Computation and Optimization of IAM Performance and Customer Satisfaction

statistical analysis concerning the choice of relevant indicators for each axis. The data was sorted and filtered with respect to its influence upon the axes. In principal, a variable was associated with an axis if it influenced the most (which was given by the absolute value of the correlation). This procedure excluded a part of the collected data as not or very little influencing the performance, limiting the irrelevant measures to the performance.

Table 4. Model IV - Principal Component Analysis (Component Matrix)

\begin{tabular}{|l|c|c|c|c|c|c|c|}
\hline & \multicolumn{7}{|c|}{ Component } \\
\cline { 2 - 8 } & 1 & \multicolumn{1}{|c|}{2} & \multicolumn{1}{c|}{4} & \multicolumn{1}{c|}{5} & \multicolumn{1}{c|}{6} & 7 \\
\hline $\begin{array}{l}\text { Presence and proportion } \\
\text { of dedicated funds. }\end{array}$ & .699 & .523 & -.034 & -.346 & .201 & .123 & .116 \\
\hline $\begin{array}{l}\text { Training and } \\
\text { qualification of the asset } \\
\text { manager. }\end{array}$ & .773 & .083 & .105 & -.034 & -.009 & .374 & -.232 \\
\hline $\begin{array}{l}\text { Quality of selected } \\
\text { titles. }\end{array}$ & .576 & .670 & -.213 & -.316 & .073 & .004 & .004 \\
\hline $\begin{array}{l}\text { Retrocessions of } \\
\text { custodian banks. }\end{array}$ & -.036 & .811 & .356 & -.258 & .139 & -.284 & -.120 \\
\hline Managed amounts. & -.081 & .693 & .420 & -.393 & .105 & -.278 & -.217 \\
\hline $\begin{array}{l}\text { Independence vis-à-vis } \\
\text { custodian banks. }\end{array}$ & -.046 & .761 & .338 & -.359 & .124 & -.305 & -.052 \\
\hline $\begin{array}{l}\text { Quality of selected } \\
\text { titles. }\end{array}$ & .547 & .377 & .345 & .307 & -.154 & -.143 & .456 \\
\hline $\begin{array}{l}\text { Ability to solve } \\
\text { problems. }\end{array}$ & -.326 & .343 & .557 & .180 & .371 & -.001 & .318 \\
\hline $\begin{array}{l}\text { Quality of the } \\
\text { transaction execution. }\end{array}$ & .052 & .222 & -.073 & .208 & .694 & -.238 & .475 \\
\hline $\begin{array}{l}\text { Access to the computer } \\
\text { system. }\end{array}$ & .328 & .072 & .166 & .198 & .667 & -.456 & -.066 \\
\hline $\begin{array}{l}\text { Performance of } \\
\text { Managed Portfolios. }\end{array}$ & .199 & .158 & .869 & .092 & .038 & .237 & .005 \\
\hline $\begin{array}{l}\text { Maintaining the } \\
\text { reputation. }\end{array}$ & .394 & .130 & .238 & .162 & -.186 & .599 & -.299 \\
\hline
\end{tabular}

Extraction Method: PCA.

a 7 components extracted.

The PCA is used to correctly assign the variables to each of the axes chosen for the model. As in the table above the highest value with respect to the seven selected components gives the membership to a specific axis.

The below figure 5 - model IV illustrates the relationships between the axes and the different variables selected for these model. Each axis represents a strategic 
Florentina Balu, Julien Froidevaux, Florina Bran, Carmen Valentina Rădulescu, Dumitru Alexandru Bodislav

perspective in the below optimal model of a hypothetical ABCD independent asset management company. We can observe both structural model (inner model) and measurement model (outer model) as well as the cause-and-effect chain (direction model).As a general rule, a weight of 0.7 or more is considered significant.

The following table summarize the SEM-PLS evaluation criteria for the model IV. All results are derived from the SmartPLS statistical software used for data analysis(Ringle, et al., 2015). All these indicators returned values higher than 0.7 (respectively higher than 0.5 in case of AEV -average extracted variance) who gives us the possibility to validate this model and declares this the optimal model for our $\mathrm{ABCD}$ independent asset management company.

Table 5. Model IV - Optimal Model. Summary of Evaluation Criteria

\begin{tabular}{|l|c|c|c|c|}
\hline & $\begin{array}{c}\text { Cronbach's } \\
\text { Alpha }\end{array}$ & Rho_A & $\begin{array}{c}\text { Composite } \\
\text { Reliability }\end{array}$ & AEV \\
\hline $\begin{array}{l}\text { External } \\
\text { factors }\end{array}$ & 0.738 & 0.822 & 0.831 & 0.630 \\
\hline $\begin{array}{l}\text { Independence } \\
\text { of society }\end{array}$ & 0.771 & 0.792 & 0.847 & 0.529 \\
\hline $\begin{array}{l}\text { Asset } \\
\text { Management } \\
\text { Model }\end{array}$ & 0.767 & 0.781 & 0.842 & 0.518 \\
\hline $\begin{array}{l}\text { Performance } \\
\text { and customer } \\
\text { satisfaction }\end{array}$ & 0.791 & 0.840 & 0.868 & 0.629 \\
\hline $\begin{array}{l}\text { Customer } \\
\text { characteristics }\end{array}$ & 0.720 & 0.720 & 0.877 & 0.781 \\
\hline $\begin{array}{l}\text { Customer } \\
\text { service }\end{array}$ & 0.814 & 0.823 & 0.857 & 0.551 \\
\hline $\begin{array}{l}\text { Company } \\
\text { structure }\end{array}$ & 0.804 & 0.808 & 0.886 & 0.721 \\
\hline
\end{tabular}

Source: own computations

In relation to this optimal model for the hypothetical ABCD asset management company, in terms of positioning, certain important recommendations can already be stated: Maintain considerable agility and flexibility vs. the largest players in the market; Occupy sectors and markets less covered by large institutions; Avoid standardization of services, and find a real added value based on a unique competence; Maintain substance and financial stability of the company; Guarantee a real, demonstrable, observable, and lasting independence; Maintain perfect reputation and training, beyond future requirements imposed by the regulator; Invest in quality time with clients; Keep the human being at the centre of the relationship. 
Independent Assets Managers in Swiss Financial Market. Modelling, Computation and Optimization of IAM Performance and Customer Satisfaction

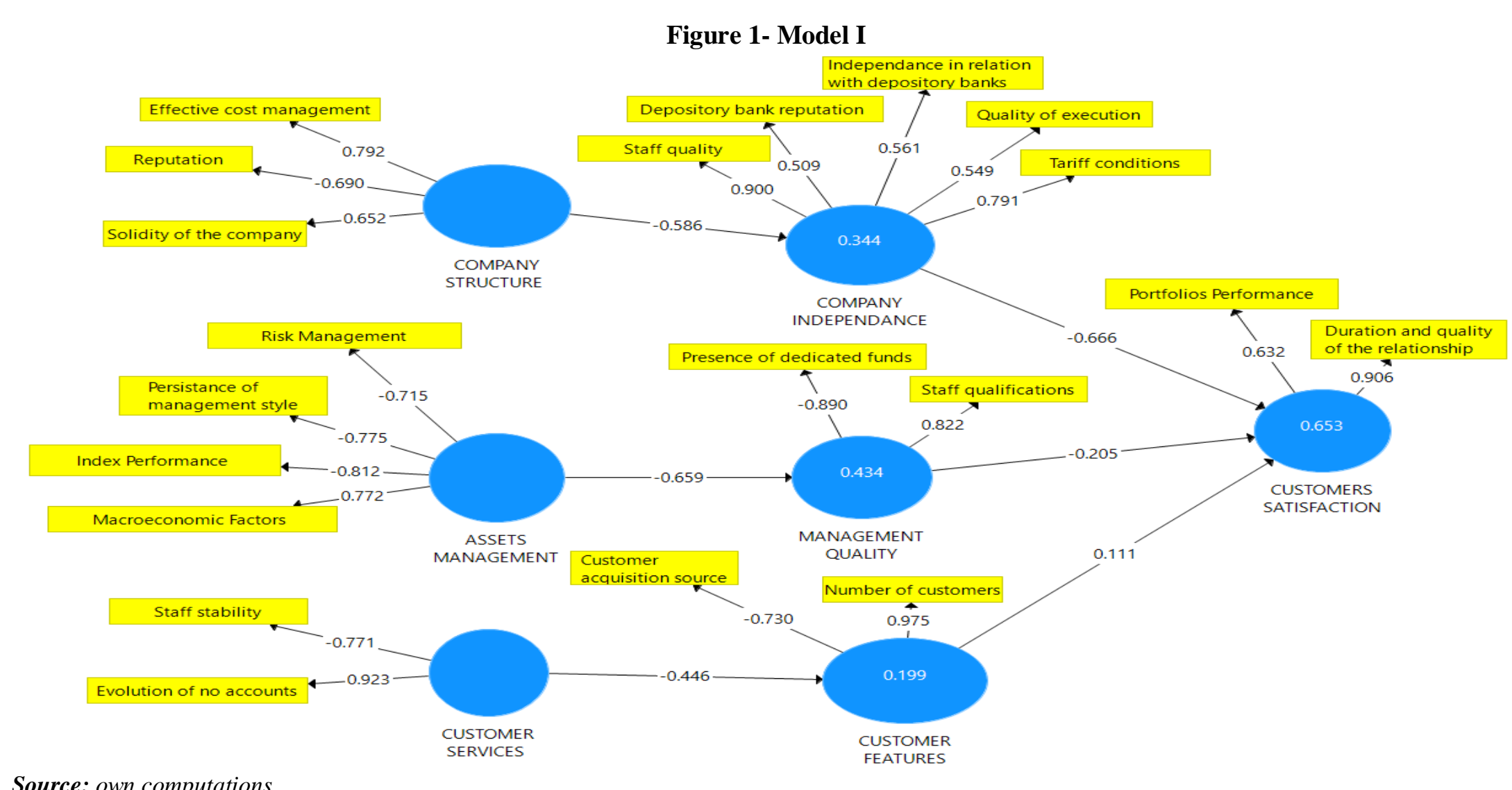




\section{Figure 5 - Model IV}

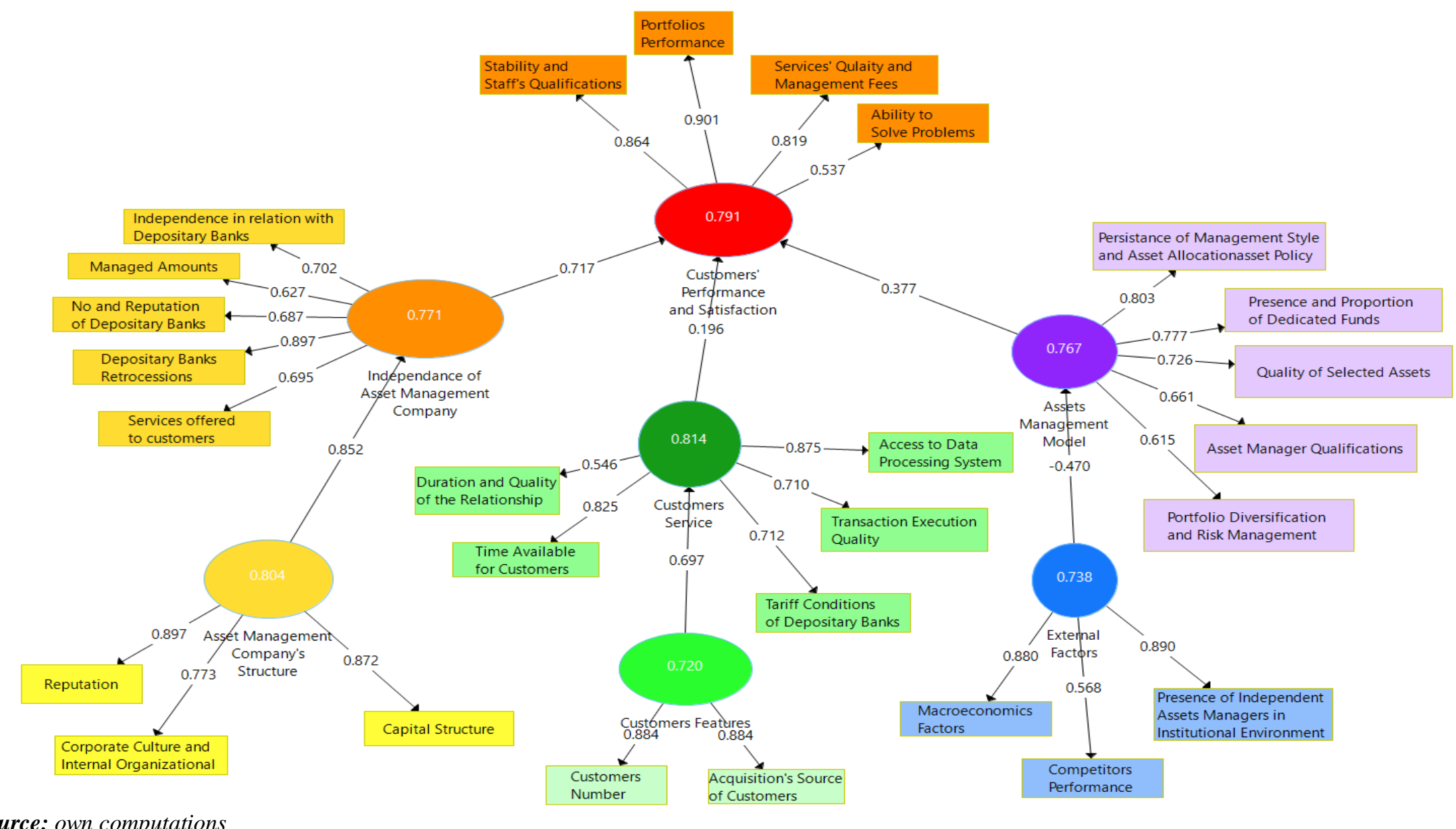

Source: own computations 
Independent Assets Managers in Swiss Financial Market. Modelling, Computation and Optimization of IAM Performance and Customer Satisfaction

\section{Conclusions}

In conclusion, the results of our research come to indicate an enormous diversity and lack of homogeneity in the market of financial intermediaries, especially within independent asset managers' area. The average size of an IAM company isaround3-5 individuals, but the market also displays structures of more than 50 people. Pure asset managers with strong investment convictions work side by side with more traditional client driven managers, the latter with a stronger focus on service, not on sharp investment management. Platforms - with dozens of managers without a common culture and centralized management as within larger banks - evolve in parallel with family-like structures that have been active for several decades. The notion of independence is difficult to define as it is subject to several definitions and interpretations, but its importance is not called into question, when it comes to the number of depository banks used, the method of remuneration and its transparency (for retrocessions in particular), or to the management style via dedicated products.

Whether in Europe or Switzerland, the evolution of regulation is clearly moving towards greater transparency but also towards higher administrative burdens. The beginning of the $21^{\text {st }}$ century marks a likely irreversible change: the end of banking secrecy, which also marks the end of an unlikely business model: with a very light structure, little regulation and very little capital requirement, an independent manager could benefit from an exceptional remuneration, in a world of financial intermediaries already subject to very high income. The sharp decline in margins and the increase in responsibilities required for the practice of the profession ultimately resulted in the reduction of the number of historical players in the market. The arrival of new highly professional players has meant that the consolidated number of independent managers has not collapsed. The consolidation of the industry announced for 20 years has not happened. It is more accurate to speak about an important evolution of the profession. The constant presence for more than 25 years of independent asset managers in the Swiss financial centre is a clear sign of vitality. In quantitative terms, the models developed through PLS regressions show the robustness of the relationship between the management structure, portfolio performance, and customer service, as well as other axes such as asset management mode, customer characteristics, independence, or external factors. The final model developed has an explanatory power above $83 \%$.In relation to the optimal model for an hypothetical ABCD asset management company, in terms of positioning, certain recommendations can already be stated: Maintain considerable agility and flexibility vs. the largest players in the market; Occupy sectors and markets less covered by large institutions; Avoid standardization of services, and find a real added value based on a unique competence; Maintain substance and financial stability of the company; Guarantee a real, demonstrable, observable, and lasting independence; Maintain perfect reputation and training, beyond future requirements imposed by the regulator; Invest in quality time with clients ; Keep the human being at the centre of the relationship.

DOI: $10.24818 / 18423264 / 52.2 .18 .04$ 
Florentina Balu, Julien Froidevaux, Florina Bran, Carmen Valentina Rădulescu, Dumitru Alexandru Bodislav

\section{REFERENCES}

[1] Adams, J.C. et Mansi, S. et Nishikawa, T. (2010), Internal Governance Mechanisms and Operational Performance: Evidence from Index Mutual Funds. The Review of Financial Studies, / v 23 n 3 2010, p.1261-1286;

[2] Baromètre bancaire 2015. L'évolution conjoncturelle des banques en Suisse. Association Suisse des Banquiers (ASB), septembre 2015;

[3] Bollen, K. (2011), Evaluating Effect, Composite, and Causal Indicators in Structural Equation Models; MIS Quarterly. Jun2011, Vol. 35 Issue 2, p.359-372;

[4] Boston Consulting Group. Global asset management market-sizing database, 2015;

[5] Bretton-Chevalier, C. (2002), Le gérant de fortune indépendant : rapport avec le client, la banque dépositaire, obligations et responsabilités. Schulthess ;

[6] Chin, W.W. (1998), The Partial Least Squares Approach to Structural Equation Modeling. In G.A. Marcoulides [ed.]. Modern Methods for Business Research, pp. 295-336. Mahwah, NJ: Lawrence Erlbaum Associates Publisher;

[7] Cremers, M., Driessen, J., Maenhout, P. et Weinbaum, D. (2009), Does Skin in the Game Matter? Director Incentives and Governance in the Mutual Fund Industry; Journal of Financial and Quantitative Analysis, vol.44, no 6, p.1345-1373.

[8] Fischer, P. (2011), Toutes les rétrocessions ne sont pas égales devant la loi. Commentaires, Centre de droit bancaire et financier, Université de Genève ;

[9] Fondation Genève Place Financière (2016), Enquête conjoncturelle Résultats 2016-2017;

[10] Hair, J., Hult, T., Sarstedt, M. et Ringle, C. (2014), A Primer on Partial Least Squares Structural Equation Modeling (PLS-SEM); Sage Publishing;

[11] Kempf, A., Ruenzi, S. et Thiele, T. (2009), Employment Risk, Compensation Incentives, and Managerial Risk Taking: Evidence from the Mutual Fund Industry; Journal of Financial Economics, 2009, vol. 92, p.92-108;

[12] KPMG. Clarity on performance of Swiss private banks (2016);

[13] La gestion de fortune en pleine mutation. Rapport de l'Association Suisse des Banquiers (ASB), novembre 2015 ;

[14] Morard, B., Balu, F.O. (2009), Developing a Practical Model for Calculating the Economic Value Added. Economic Computation and Economic Cybernetics Studies and Research. ASE Publishing; Volume 43, Issue 3, pp. 107-122;

[15] Morard, B., Stancu, A., Jeannette, C. (2012), The Relationship between Structural Equation Modelling and Balanced Scorecard: Evidence from a Swiss Non-Profit Organisation. Review of Business \& Finance Studies, v.3(2) pp. 21-37, 2012;

[16] Oberlechner, T. (2007), The Psychology of Ethics in the Finance and Investment Industry; Research Foundation of the CFA Institute.

[17] Ringle, C. M. et al.(2015), SmartPLS 3. Bönningstedt: SmartPLS GmbH;

[18] Stewart, S. (2013), Manager selection; Research Foundation of the CFA Institute;

[19] Stoughton N.M. et WU Y. et Zechner J. (2011), Intermediated Investment Management; The Journal of Finance, June 2011, vol. LXVI, no.3, p.947-979;

[20] Walter, I. (2015), The Industrial Organization of the Global Asset Management Business; Research Foundation of the CFA Institute, 2015. 